\title{
OCCUPATIONAL SHOULDER DISABILITY: FUNCTIONAL RECOVERY AFTER DECOMPRESSION AND NEUROLYSIS OF THE UPPER BRACHIAL PLEXUS AND THE LONG THORACIC NERVE
}

\section{RAHUL K. NATH, ALYSSA M. LEAL, and CHANDRA SOMASUNDARAM}

Texas Nerve and Paralysis Institute, Houston, USA

Research Division

\begin{abstract}
Objectives: This study aimed to assess the surgical outcomes of patients with work-related upper extremity musculoskeletal disorders (UE-MSDs) who failed conservative treatment. Material and Methods: This was a retrospective study of 17 patients who had work-related UE-MSDs and underwent the following surgeries and follow-up evaluations: decompression, external and internal neurolysis of the upper trunk of the brachial plexus and the long thoracic nerve (LTN), and a partial resection of the anterior and middle scalene muscle. A detailed history of clinical presentation including pain, physical and clinical examinations of the extent of scapular winging (ESW), and upper extremity anatomical postures, such as active forward arm flexion and shoulder abduction, were recorded before and after 3 months of the surgery. Nerve conduction velocity and electromyography examination reports were obtained to assess the sensory or motor loss of the nerve injury before their operation. Results: All 17 patients included in this report showed some improvement anatomically in the scapula appearance and functionally in their shoulder movements. More specifically, $9(53 \%)$ patients got a restored to near healthy appearance of the scapula, and $11(65 \%)$ patients recovered a full range of motion, $180^{\circ}$ post-surgically. Overall, the mean shoulder flexion and abduction improved to $157 \pm 37.5^{\circ}$ and $155 \pm 40.2^{\circ}$ after the surgery from $106 \pm 30.2^{\circ}$ and $111 \pm 34.8^{\circ}$, respectively $(\mathrm{p}<0.0001)$. The ESW score also significantly improved from a mean of $1.5 \pm 0.51$ to $3.5 \pm 0.71$ ( $\mathrm{p}<0.0001)$. The post-surgical improvements were statistically highly significant $(\mathrm{p}<0.0001)$. Conclusions: Decompression and neurolysis of the upper brachial plexus and the LTN, and the partial release of the scalene muscle contracture procedures have fostered improvements in the shoulder anatomical appearance and movements in all $17 \mathrm{pa}-$ tients. Int J Occup Med Environ Health. 2021;34(3):427-35
\end{abstract}

Key words:

shoulder injury, winging scapula, musculoskeletal disorders, occupational injury, anatomical postures, shoulder movements

\section{INTRODUCTION}

Work-related upper extremity musculoskeletal disorders (UE-MSDs) in various manufacturing, construction, and service settings show that they are cost-effective, causing disability, chronic pain, decreased productivity, poor performance, work absenteeism/sick leave, unemployment and workers' compensation claims. Further, UE-MSDs affect the socioeconomic status and quality of life in these patients [1-9]. It is a global concern; about 11.2 million U.S. workers were found to suffer from UE-MSDs, and the annual incidence was found to increase [1]. Ma et al. [1] and other investigators reported that construction [9] and automobile manufacturing industrial workers [10] had the highest prevalence of UE-MSDs. These diseases affect millions of healthcare and office workers, as well [8].

Received: March 30, 2020. Accepted: October 29, 2020

Corresponding author: Rahul K. Nath, Texas Nerve and Paralysis Institute, Research Division, 6400 Fannin St., Houston, Texas-77030, USA (e-mail: drnath@drnathmedical.com). 
Although the etiology of UE-MSDs is multifactorial, injuries typically occur due to acute macrotrauma (accidents/ falls) or chronic repetitive microtraumatic overuse [3]. Many jobs still require workers to perform repetitive tasks or to carry or handle heavy materials. Yung et al. [4] reported that cumulative neuromuscular fatigue might result from exposure to physically demanding work, for example, plumbing, and repetitive and sustained work with insufficient recovery. Upper brachial plexus and long thoracic and accessory nerve injuries can give permanent disabilities such as abnormal shoulder appearance and posture (scapular winging), weakness, and dysfunction of the shoulder muscles and joints with limited upper extremity functional movements and sometimes severe pain [11-14]. Injuries to the long thoracic nerve (LTN) that innervates the serratus anterior muscle are a common cause of scapular winging. In fact, the LTN is more susceptible to injury as it is superficial, long, and small in diameter. An unusual case of scapular winging caused by a dorsal scapular nerve injury combined with a suprascapular nerve injury has been reported recently [15].

The scapula plays a significant role in the upper extremity stability and movements, as it is a part of the shoulder joint and girdle. Scapular winging and abnormal scapular movements are indicative of shoulder dysfunction. The compensatory muscle activity required to maintain scapular stability is associated with pain, spasm, and tendonitis around the shoulder joint [16,17].

There are numerous reports on the surgical treatment of multilevel nerve compression and muscle contractures in patients with UE-MSDs [18-22]. Other investigators and the authors of this article have previously demonstrated the successful management of the winging scapula and limited shoulder range of motion (ROM) in young athletes and adult patients with UE-MSDs [18-22]. Functional improvements after decompression and neurolysis of the upper brachial plexus and the LTN were reported in 17 occupational injury patients with UE-MSDs.

\section{MATERIAL AND METHODS}

This was a retrospective study of 17 patients who had work-related UE-MSDs and underwent the surgical management and follow-up evaluations.

\section{Type of examination and scales used for evaluation}

The initial patient evaluation included patients' demographics (gender, age), and a detailed medical history for all 17 patients (the cause and onset of the injury, the side of the injury [left/right or bilateral], symptoms including the severity of pain [mild, moderate or severe], and patients' previous and current therapies). Nerve conduction velocity and electromyography examination reports were obtained for the patients to assess the regional sensory or motor loss of the nerve injury.

The authors performed both physical and clinical examinations of these patients. Theleadauthor and the operatingsurgeon $(\mathrm{RKN})$ performed physical examinations of these patients for scapular winging. The male patients were asked to remove their shirts, and the female patients were asked to wear halter tank tops during the physical examination of the winging scapula/posterior thorax. The authors assessed the extent of scapular winging (ESW) while the patient forward flexed his/her arms to the horizontal plane (Figure 1a), and pushed on a wall in a pushup motion. A 4-point numerical scale for determining the ESW, i.e., 1 - severe; 2 - moderate; 3 - mild; and 4 - minimal/normal, was adopted as shown in Figure 2.

The patients were asked to send a short video of the following movements by filming them from behind without a shirt (males) or with a halter tank top (females), so that the shoulder blade could be visible. Also, the authors took a video of these patients performing the following movements during the patient's clinics, and before and after the surgery.

- Movement 1: the patients were asked to raise their arms straight in front at a right angle to their body and then as high as possible, and return them to the resting position in the same way. 
a)

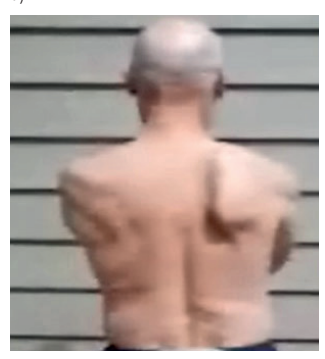

b)

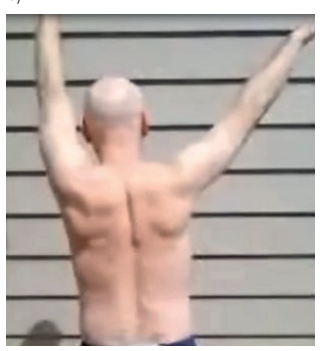

c)

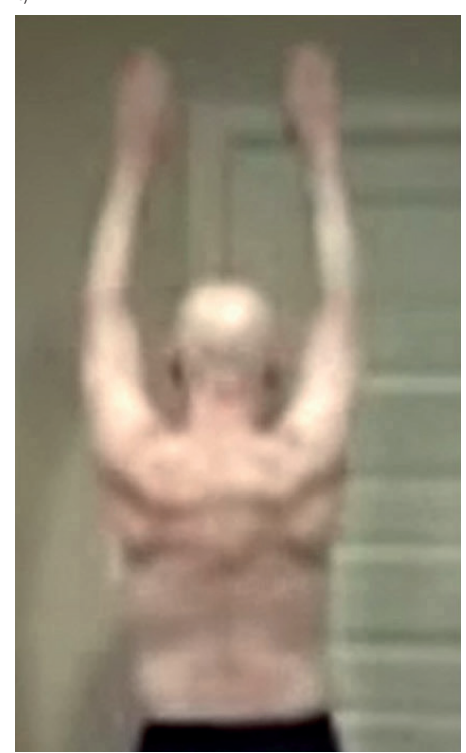

Figure 1. Pre- and post-surgical images of a 61-year-old male patient with scapular winging due to heavy lifting for an extended period as an airline pilot: a) scapular winging; b) muscle weakness, and limited shoulder movement in his right upper extremity; c) post-surgical recovered active range of motion (shoulder abduction and flexion) to $180^{\circ} 10$ months after decompression and neurolysis of the upper brachial plexus and the long thoracic nerve, and a partial resection of the scalene muscle procedures

- Movement 2: the patients were asked to raise their arms to the side through a "T" position and then as high as possible, and return them to the resting position through the same "T" position.

- Movement 3: facing a wall, the patients were asked to raise their arms to the front at a right angle to their body, and continue to raise as high as possible above their head (as in movement 1). And then, they had to take them down to the side through a " $T$ " position (as in movement 2), without bringing their arms completely down and then to return them to the front. Then, they were asked to perform a press-up against a wall.

Stills were taken from the video of these patients performing these movements $\left(0^{\circ}\right.$ being relaxed at the side and $180^{\circ}$ being fully abducted above the head). They were evaluated for 2 distinct motions: shoulder flexion in the sagittal

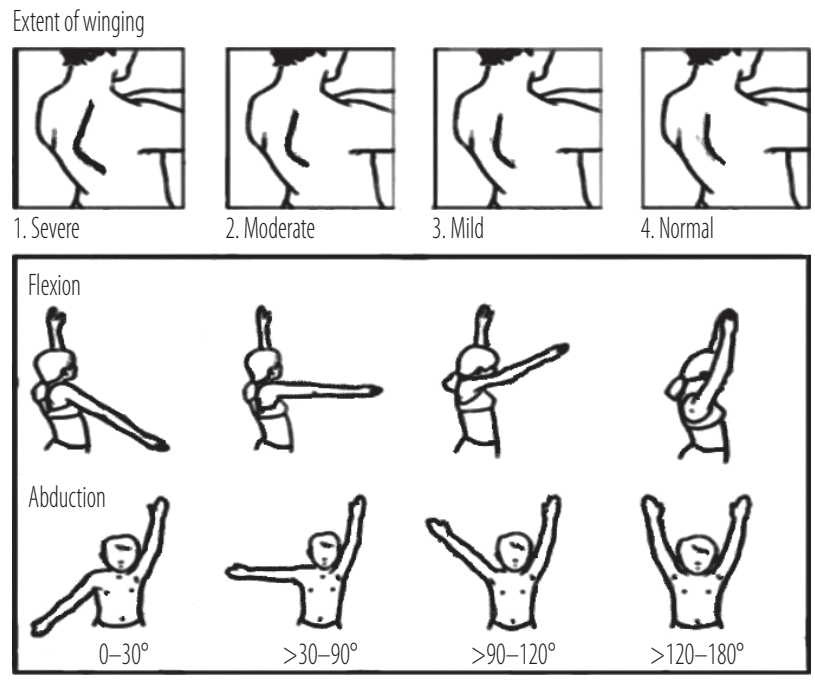

Figure 2. Schematic illustrations of the extent of scapular winging and shoulder abduction and flexion

plane and abduction in the frontal plane while videotaped from the posterior and superior views (Figures 1 and 2).

All statistical tests were performed using paired Student's t-test with Analyze-it 2.12 software in Excel 2003 (Analyzeit, Leeds, UK; Microsoft, Redmond, WA, USA). A value of $p<0.05$ was considered statistically significant.

The patients were treated ethically in compliance with the Declaration of Helsinki. Documented informed consent was obtained from all patients.

\section{Operative procedures}

Scar removal and a partial release of muscle contractures:

- decompression and neurolysis of the upper brachial plexus and the LTN,

- partial release of the impinging or contracted muscles such as the anterior scalene and the middle scalene.

The patient was brought to the operating room where general anesthesia was performed. The patient's neck was prepped and draped in the usual sterile fashion. An incision was created over the area where the LTN exited through the middle scalene muscle, about $3 \mathrm{~cm}$ superior to the upper clavicular border. Dissection proceeded down 
through the skin and soft tissue into the platysma muscle. The platysma was divided and retracted. The supraclavicular nerves were identified and retracted laterally. The upper trunk of the brachial plexus was identified deep in the scalene fat pad. The fat pad was retracted, and the underlying upper trunk of the brachial plexus was identified. This appeared to have a quite thick epineurial scar with delicate superficial blood vessels and neovascularization consistent with the stretch injury to the upper trunk. This explained the weakness in the deltoid and spinati, as well as the biceps. Thickened epineurium was released through a microsurgical technique, which was external neurolysis. Microscopic guidance was used throughout.

The substance of the upper trunk was entered, and the perineurium dissected using microsurgical instrumentation and high magnification. Major fascicle groups were separated through internal neurolysis to decompress the upper trunk internally. The upper trunk was decompressed surgically by a partial release and excision of the anterior scalene muscle. Dissection proceeded around the lateral and posterior aspects of the upper trunk, where the LTN was identified exiting the middle scalene muscle. The LTN also was noted to have an hourglass-shaped impingement at this exit point, and the nerve was externally neurolysed in a circumferential fashion using microsurgical technique.

The substance of the LTN was entered, and the perineurium dissected. Several fascicles were separated through internal microneurolysis to decompress the nerve internally. The middle scalene muscle was resected partially to decompress the LTN. Direct electrical stimulation seemed to show an improvement in the conduction to the serratus anterior muscle following the surgery, based on intraoperative monitoring. Next, a 6 -cm incision was made into the affected upper lateral chest to access the chest wall. Dissection proceeded to the chest wall, where the LTN was encountered. Compressive, crossing blood vessels and connective tissue bands were released sharply to decompress the nerve. External neurolysis and internal neurolysis were performed further to release the scarring of the nerve in the operative field. High magnification and meticulous microsurgical techniques were used throughout.

After a thorough irrigation with antibiotic saline and with meticulous maintenance of hemostasis throughout, the wounds were closed in layers with absorbable suture. Dry dressings were applied, and the patient was awake, alert, and stable following the surgery. The patient was delivered from the operating room in a good condition. Blood loss was minimal, and there were no complications.

\section{RESULTS}

The authors reported the surgical outcomes of all 17 patients (10 men and 7 women) who had post-surgical follow-up evaluations at 2.5-29 months. The time between the onset of symptoms and the surgery ranged from 3 months to $>7$ years. The average patient age at the time of the surgery was 39 years (range: 22-61 years). The patients represented almost all industries: construction, healthcare, food/ restaurant, travel (airline), office, and other service settings. Eight of 17 patients (47\%) in this group had developed the lesion due to physical exertion such as lifting, pushing and pulling, and carrying heavy materials; $6(35 \%)$ patients had had accidents (Table 1).

Pre-operatively, the ESW was severe in 9 of 17 patients $(53 \%)$ and moderate in 8 patients $(47 \%)$ (Table 2 and Figure 1a). Shoulder abduction and flexion were about $90^{\circ}$ in 9 patients and $120^{\circ}$ in 6 patients before the surgery. One patient had a weak shoulder ROM of only $30^{\circ}$ presurgically. The shoulder ROM was normal in 1 patient, but that patient had pain and a moderate scapular winging. Overall, the mean shoulder flexion and abduction were $106^{\circ} \pm 30.2$ and $111^{\circ} \pm 34.8$, pre-operatively (Table 2 and Figure 1b).

All 17 patients included in this report got improvement anatomically in the appearance of their winged scapula, 
Table 1. Demographics of the patients with work-related scapular winging and limited shoulder movements, who underwent decompression and neurolysis of the upper brachial plexus and the long thoracic nerve, and follow-up evaluations at the Texas Nerve and Paralysis Institute, Houston, USA, in 2007-2020

\begin{tabular}{|c|c|c|c|c|c|c|}
\hline \multirow{3}{*}{$\begin{array}{l}\text { Patient } \\
\text { No. }\end{array}$} & \multirow{3}{*}{ gender } & \multicolumn{3}{|c|}{$\begin{array}{l}\text { Participants } \\
(\mathrm{N}=17)\end{array}$} & \multirow{3}{*}{$\begin{array}{l}\text { time between } \\
\text { the onset } \\
\text { and surgery } \\
\text { [years] } \\
(\mathrm{M}=2.1)\end{array}$} & \multirow[b]{3}{*}{ causation } \\
\hline & & \multirow[b]{2}{*}{$\begin{array}{l}\text { injury } \\
\text { side }\end{array}$} & \multicolumn{2}{|c|}{$\begin{array}{c}\text { age } \\
\text { [years] }\end{array}$} & & \\
\hline & & & $\begin{array}{c}\text { at injury } \\
(\mathrm{M}=36.6)\end{array}$ & $\begin{array}{c}\text { at surgery } \\
(\mathrm{M}=38.6)\end{array}$ & & \\
\hline 1 & $\mathrm{M}$ & $\mathrm{L}$ & 21.7 & 23.5 & 1.8 & reached overhead and pulled an object \\
\hline 2 & $\mathrm{~F}$ & $\mathrm{~L}$ & 27 & 27.9 & 0.9 & working as a photographer and carrying heavy objects and bags \\
\hline 3 & $\mathrm{~F}$ & $\mathrm{R}$ & 33 & 34.1 & 1.1 & writing for $3 \mathrm{~h}$ \\
\hline 4 & $\mathrm{~F}$ & $\mathrm{R}$ & 48 & 49.9 & 1.9 & fell-slipped at work while carrying a heavy piece of meat \\
\hline 5 & $\mathrm{~F}$ & $\mathrm{R}$ & 30 & 37.4 & 7.4 & $\begin{array}{l}\text { an X-ray unit fell out of the wall on her shoulder } \\
\text { (an accident at work) }\end{array}$ \\
\hline 6 & $\mathrm{~F}$ & $\mathrm{~L}$ & 48 & 53.9 & 5.9 & lifting heavy objects (a workers' compensation program) \\
\hline 7 & M & $\mathrm{R}$ & 61.3 & 61.6 & 0.3 & working as an airline pilot (an accident at work) \\
\hline 8 & $\mathrm{~F}$ & $\mathrm{R}$ & 39 & 43 & 4.0 & fall (a workers' compensation program) \\
\hline 9 & M & $\mathrm{R}$ & 23 & 23.6 & 0.6 & lifting newspaper bundles (25-30 lbs) at work \\
\hline 10 & M & $\mathrm{L}$ & 21 & 22.1 & 0.2 & snow shoveling \\
\hline 11 & $\mathrm{M}$ & $\mathrm{R}$ & 31 & 32.9 & 1.9 & twisted his shoulder at work \\
\hline 12 & M & $\mathrm{L}$ & 37.3 & 40.1 & 2.8 & fell off an airplane at military \\
\hline 13 & $\mathrm{~F}$ & $\mathrm{R}$ & 56 & 56.8 & 0.8 & lifting heavy bags at work \\
\hline 14 & M & $\mathrm{R}$ & 43 & 44.2 & 1.2 & industrial injury: lifting and carrying cement forms \\
\hline 15 & M & $\mathrm{R}$ & 24.1 & 24.8 & 0.7 & lifting boards at work (hanging sheet rocks) \\
\hline 16 & M & $\mathrm{R}$ and $\mathrm{L}$ & 42 & $42.5,43.2$ & $0.5,1.2$ & pulled his arm after his clothes had been caught in a generator \\
\hline 17 & M & $\mathrm{R}$ & 42 & 43.9 & 1.9 & laying down for long hours at his back, drilling to install cabinets \\
\hline
\end{tabular}

and achieved their shoulder movements after the decompression and neurolysis of the upper brachial plexus and the LTN. Eight of 17 patients (47\%) got restored to or maintained a near-normal position of their scapula after the surgery. The other $9(53 \%)$ patients experienced a moderate improvement from severe winging of the scapula. Eleven of 17 patients $(65 \%)$ recovered their full ROM $180^{\circ}$ or near-perfect shoulder abduction post-operatively (Table 2 and Figure 1c). The mean shoulder flexion and abduction improved significantly to $157^{\circ} \pm 37.5$ and $155^{\circ} \pm 40.2$ after the surgery from $106^{\circ} \pm 30.2$ and $111^{\circ} \pm 34.8$, respectively ( $\mathrm{p}<0.0001)$. The ESW score also significantly im- proved from a mean of $1.5 \pm 0.51$ to $3.5 \pm 0.71$ ( $p<0.0001$ ). Overall, the post-surgical improvements were statistically highly significant ( $<<0.0001)$, as shown in Table 2.

\section{DISCUSSION}

Return to work (RTW) is the goal of the successful management of employees with MSDs who are off sick [23]. The treatment of repetitive strain injury-related MSDs remains challenging because the pathological processes are complex and involve many biopsychosocial factors [24]. In response to a musculotendinous exertion or an injury, several inflammatory signaling molecules (cytokines) are 


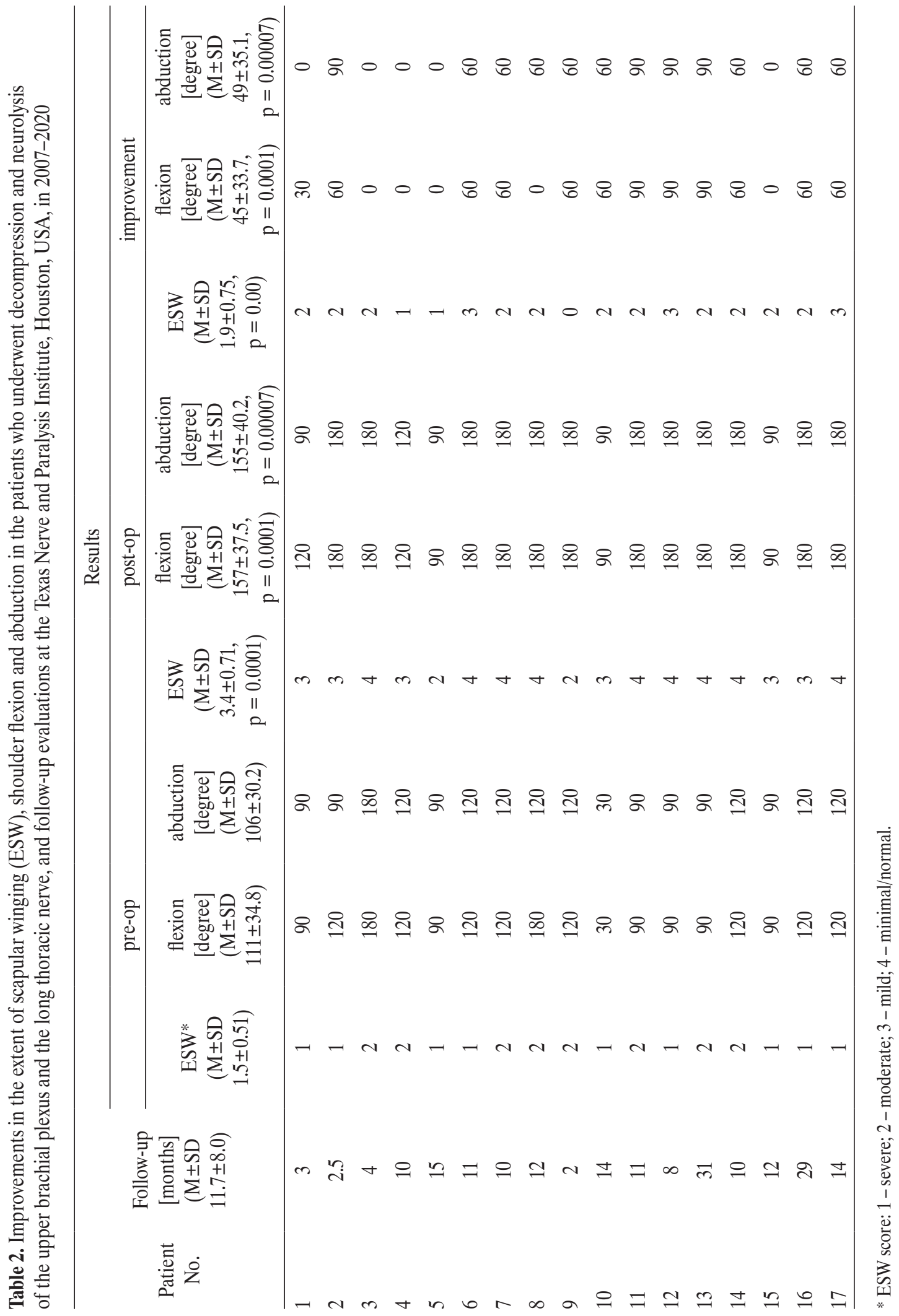


released directly from the involved skeletal muscle(s) and tendon(s) or the surrounding fascial tissues, causing tissue damage and fibrosis [25]. Enhanced intraneural inflammation and nerve fibrosis were shown in the high-repetition high-force treadmill group compared to the control group [26]. It was also shown to correlate with increasing pain and tingling.

Reconstructive and orthopedic surgeries play a significant role in RTW and the workers' compensation system because many occupational injuries are neuromuscular and musculoskeletal [27]. Other investigators and the authors of this article have previously demonstrated the effective surgical treatment of multilevel nerve compression and muscle contractures in patients with UE-MSDs [18-22]. Clinical and functional outcomes play a significant role in predicting RTW after the surgery.

Among 17 patients included in this report, $12.5 \%$ were involved in a workers' compensation program, 2 were from the construction industry and none from the automobile industry, although construction [1] and automobile manufacturing industrial workers [6,10] are reported to have a higher incidence of these injuries and disabilities. In addition, $18 \%$ of the patients in this study group were from an office setting and 1 patient was from the healthcare industry, who had had an accident (an X-ray unit fell out of the wall on that person's shoulder). Finally, a hairdresser was included in this study who had had repetitive movements and abnormal positioning during her work. Prolonged abnormal postures/positions can result in chronic nerve compression, affecting neural and other soft tissues [28].

Young and less experienced, as well as temporary workers have been found to have an increased risk of workplace injury [9]. All of the patients involved in this study were aged $>21$ years. More specifically, 38\% of the patients were aged $<30$ years and $62 \% 31-61$ years. The authors did not have the patients' work history to determine how experienced they were and whether they were temporary or permanent employees at the time of injury.
Despite some educational programs, study reports, training, and safety precautions, a considerable number of falls and accidents still happen in work environments. Overall, $35 \%$ of the patients involved in this study had injuries that needed surgical treatments resulting from falls and other accidents. All 17 patients in this report got some improvement anatomically in the appearance of their winged scapula and achieved their functional shoulder movements after scar removal and scalene muscle resection operations.

\section{CONCLUSIONS}

Decompression and neurolysis of the upper brachial plexus and the LTN, and the partial release of the scalene muscle contracture procedures, have fostered improvements in shoulder anatomical appearance and movements in all 17 patients.

\section{ACKNOWLEDGMENTS}

The authors would like to thank the patients, and their families, who participated in this study.

\section{REFERENCES}

1. Ma CC, Gu JK, Charles LE, Andrew ME, Dong RG, Burchfiel CM. Work-related upper extremity musculoskeletal disorders in the United States: 2006, 2009, and 2014 National Health Interview Survey. Work. 2018;60(4):623-34, https:// doi.org/10.3233/WOR-182770.

2. Depreli O, Angin E. Review of scapular movement disorders among office workers having ergonomic risk. J Back Musculoskelet Rehabil. 2018;31(2):371-80, https://doi.org/10.3233/ BMR-170790.

3. Llopis E, Restrepo R, Kassarjian A, Cerezal L. Overuse Injuries of the Wrist. Radiol Clin North Am. 2019;57(5):957-76, https://doi.org/10.1016/j.rcl.2019.05.001.

4. Yung M, Bigelow PL, Hastings DM, Wells RP. Detecting within- and between-day manifestations of neuromuscular fatigue at work: an exploratory study. Ergonomics. 2014;57(10): 1562-73, https://doi.org/10.1080/00140139.2014.934299. 
5. Evanoff B, Kaskutas V, Dale AM, Gaal J, Fuchs M, Lipscomb H. Outcomes of a revised apprentice carpenter fall prevention training curriculum. Work. 2012;41 Suppl 1:3806-8, https://doi.org/10.3233/WOR-2012-0681-3806.

6. Yang ST, Jeong BY. Comparison of accident characteristics between manual materials handling (MMH) and non-MMH works in the automobile parts manufacturing industry: Based on South Korea and the US. Work. 2019;62(2):197203, https://doi.org/10.3233/WOR-192855.

7. Greiner BA, Nolan S, Hogan DAM. Work-Related Upper Limb Symptoms in Hand-Intensive Health Care Occupations: A Cross-Sectional Study With a Health and Safety Perspective. Phys Ther. 2019;99(1):62-73, https://doi.org/10.10 93/ptj/pzy124.

8. Evanoff BA, Rohlman DS, Strickland JR, Dale AM. Influence of work organization and work environment on missed work, productivity, and use of pain medications among construction apprentices. Am J Ind Med. 2020;63(3):269-76, https://doi.org/10.3233/WOR-2012-0681-3806.

9. Clarkson L, Blewett V, Rainbird S, Paterson JL, Etherton H. Young, vulnerable and uncertain: Young workers' perceptions of work health and safety. Work. 2018;61(1):113-23, https://doi.org/10.3233/WOR-182788.

10. Ohlander J, Keskin MC, Weiler SW, Stork J, Radon K. Snapfit assembly and upper limb functional limitations in automotive production workers: a nested case-control study. Int Arch Occup Environ Health. 2019;92(6):813-9, https://doi. org/10.1007/s00420-019-01418-3.

11. Raksakulkiat R, Leechavengvongs S, Malungpaishrope K, Uerpairojkit C, Witoonchart K, Chongthammakun S. Restoration of winged scapula in upper arm type brachial plexus injury: anatomic feasibility. J Med Assoc Thai. 2009;92 Suppl 6:S244-50.

12. Suzuki K, Doi K, Hattori Y, Pagsaligan JM. Long-term results of spinal accessory nerve transfer to the suprascapular nerve in upper-type paralysis of brachial plexus injury. J Reconstr Microsurg. 2007;23(6):295-9, https://doi. org/10.1055/s-2007-985205.
13. Nath RK, Lyons AB, Bietz G. Microneurolysis and decompression of long thoracic nerve injury are effective in reversing scapular winging: long-term results in 50 cases. BMC Musculoskelet Disord. 2007;8:25, https://doi.org/10.1186/14 71-2474-8-25.

14. Coro L, Azuelos A, Alexandre A. Suprascapular nerve entrapment. Acta Neurochir Suppl. 2005;92:33-4, https://doi. org/10.1007/3-211-27458-8_8.

15. Lee SY, Lee HD, Cho YS, Han SH. Winged scapula caused by dorsal scapular neuropathy combined with suprascapular neuropathy: A case report. Medicine (Baltimore) 2018; 97(40):e12515, https://doi.org/10.1097/MD.0000000000012 515.

16. Martin RM, Fish DE. Scapular winging: anatomical review, diagnosis, and treatments. Curr Rev Musculoskelet Med. 2008;1(1):1-11, https://doi.org/10.1007/s12178-007-9000-5.

17. Seth A, Dong M, Matias R, Delp S. Muscle Contributions to Upper-Extremity Movement and Work From a Musculoskeletal Model of the Human Shoulder. Front Neurorobot. 2019;13:90, https://doi.org/10.3389/fnbot.2019.00090.

18. Zimmerman RM, Jupiter JB, Gonzalez del Pino J. Minimum 6-year follow-up after ulnar nerve decompression and submuscular transposition for primary entrapment. J Hand Surg Am. 2013;38(12):2398-404, https://doi.org/10.1016/j.jhsa.2013. 09.017 .

19. Gillick JL, Cooper JB, Babu S, Das K, Murali R. Successful Treatment of Complex Regional Pain Syndrome with Pseudoaneurysm Excision and Median Nerve Neurolysis. World Neurosurg. 2016;92:e582,e585-582,e588, https://doi. org/10.1016/j.wneu.2016.06.023.

20. Nath RK, Melcher SE. Rapid recovery of serratus anterior muscle function after microneurolysis of long thoracic nerve injury. J Brachial Plex Peripher Nerve Inj. 2007;2:4, https:// doi.org/10.1186/1749-7221-2-4.

21. Novak CB. Upper extremity work-related musculoskeletal disorders: a treatment perspective. J Orthop Sports Phys Ther. 2004;34(10):628-37, https://doi.org/10.2519/jospt.2004. 34.10.628. 
22. Disa JJ, Wang B, Dellon AL. Correction of scapular winging by supraclavicular neurolysis of the long thoracic nerve. J Reconstr Microsurg. 2001;17(2):79-84, https://doi.org/10. 1055/s-2001-12694.

23. Ellis RA, Novak CB, Mackinnon SE, Cheng CJ. Workers' compensation, return to work, and patient satisfaction after carpal tunnel decompression. Am J Orthop (Belle Mead NJ). 2007;36(4):E63-6, https://doi.org/10.5435/JAAOS-D16-00499.

24. Gold JE, Hallman DM, Hellstrom F, Bjorklund M, Crenshaw AG, Djupsjobacka M, et al. Systematic review of biochemical biomarkers for neck and upper-extremity musculoskeletal disorders. Scand J Work Environ Health. 2016; 42(2):103-24, https://doi.org/10.5271/sjweh.3533.

25. Fisher PW, Zhao Y, Rico MC, Massicotte VS, Wade CK, Litvin J, et al. Increased CCN2, substance P and tissue fibrosis are associated with sensorimotor declines in a rat model of repetitive overuse injury. J Cell Commun Signal. 2015;9(1):37-54, https://doi.org/10.1007/s12079-015-0263-0. 26. Smith TTG, Barr-Gillespie AE, Klyne DM, Harris MY, Amin M, Paul RW, et al. Forced treadmill running reduces systemic inflammation yet worsens upper limb discomfort in a rat model of work-related musculoskeletal disorders. BMC Musculoskelet Disord. 2020;21(1):57, https://doi.org/10. 1186/s12891-020-3085-z.

27. Daniels AH, Kuris EO, Palumbo MA. The Role of the Orthopaedic Surgeon in Workers' Compensation Cases. J Am Acad Orthop Surg. 2017;25(3):e45-e52,

28. Hassan OM, Bayomy H. Occupational Respiratory and Musculoskeletal Symptoms among Egyptian Female Hairdressers. J Community Health. 2015;40(4):670-9, https://doi. org/10.1007/s10900-014-9983-y.

This work is available in Open Access model and licensed under a Creative Commons Attribution-NonCommercial 3.0 Poland License - http://creativecommons.org/ licenses/by-nc/3.0/pl/deed.en. 